\title{
Modern Developments of Nano Based Drug Delivery System by Combined with Phytochemicals- Presenting New Aspects
}

\author{
Ranajit Nath ${ }^{1}$, Ratna Roy ${ }^{2}$, Gourav Barai ${ }^{3}$, Shishir Bairagi ${ }^{4}$, Supratip Manna ${ }^{5}$, Rajarshi Chakraborty ${ }^{6}$ \\ 1,3,6 Department of Pharmaceutics, NSHM Knowledge Campus, Kolkata- Group of Institutions, Kolkata, West \\ Bengal, India \\ 2,4,5 Department of Pharmacology, NSHM Knowledge Campus, Kolkata- Group of Institutions, Kolkata, West \\ Bengal, India
}

Article Info

Volume 8, Issue 4

Page Number : 107-129

\section{Publication Issue}

July-August-2021

\section{Article History}

Accepted : 02 July 2021

Published : 06 July 2021

\section{ABSTRACT}

Nanomedicine are a relatively new but quickly expanding discipline in which tiny materials are used as diagnostic instruments or to administer therapeutic drugs to particular targets in a controlled manner. Nanotechnology provides a number of advantages in the treatment of chronic human diseases by allowing precise medications to be delivered to particular locations. There have been several notable uses of nanomedicine (chemotherapeutic agents, biological agents, immunotherapeutic agents, etc.) in the treatment of various illnesses in recent years. Neverthless, In current scenario there are phytochemicals are also present whom are responsible for prevention of devastating diseases. In this review it has been highlighted that there are real possible outcomes present, in the case of the combined treatment strategies of phytochemicals and nanoparticles. Eventually, this combined drug delivery system play crucial role in anti-cancer, anti-alzehimar, anti-bacterial and many more complicated maladies. We also focused on the preclinical and clinical study regarding the drug delivery system. Here, the types of phytochemicals along with their bioavilability also mentioned. Additionally, the Nanomedicines' advantages and disadvantages in drug delivery from synthetic to natural sources to clinical applications are also explored. In addition, we've added information about nanomedicine's developments by attaching with phytochemicals with respect to the diseases and future prospects.

Keywords : Nanotechnology, nanomaterials, phytochemicals, bioavailability, activity study, future propects.

\section{INTRODUCTION}

Plant-based natural products have been widely employed as treatments against numerous diseases since ancient times. On the basis of traditional knowledge and traditions, modern medications are primarily developed from plants. Natural resources provide over a quarter of all key medicinal chemicals and derivatives available today. Natural substances with various molecular backgrounds provide a 
starting point for the development of new medications. Interest in building synthetically accessible lead molecules that mirror their counterpart's chemistry has been a recent trend in natural product-based drug discovery . Natural goods have unique qualities, such as chemical variety, chemical and biological capabilities with macromolecular specificity, and lower toxicity. As a result, they are promising leads for the identification of new medications . Additionally, computational studies have aided in the development of nextgeneration drug inventions such as target-based drug discovery and drug delivery.

Nanotechnology has been proven to bridge the gap between biological and physical sciences by employing nanostructures and nanophases in a variety of domains, particularly in nanomedicine and nano-based drug delivery systems. Nanomaterials are materials with diameters ranging from 1 to 100 nanometers that affect the frontiers of nanomedicine, from biosensors to microfluidics, drug transport, and microarray tests to tissue engineering . To produce nanomedicines, nanotechnology employs curative agents at the nanoscale level. Nanoparticles have fueled the discipline of biomedicine, which includes nanobiotechnology, medication delivery, biosensors, and tissue engineering. Nanoparticles are typically small nanospheres because they are made up of materials designed at the atomic or molecular level . As a result, they can travel more easily within the human body than larger materials. The structural, chemical, mechanical, magnetic, electrical, and biological properties of nanoscale particles are all distinct. Nanomedicine is a new area that applies nanoscience knowledge and technology to medical biology and illness prevention and treatment. It refers to the use of nanoscale materials in live cells, such as nanorobots, nanosensors, and actuation materials for diagnosis, delivery, and sensory functions (Fig. 1). For example, a nanoparticle-based technique for cancer diagnostics has been developed that combines both treatment and imaging modalities . Lipid systems like liposomes and micelles, which are currently FDAapproved, were used in the first generation of nanoparticle-based therapy . Inorganic nanoparticles such as gold or magnetic nanoparticles can be found in these liposomes and micelles. These characteristics have led to a rise in the usage of inorganic nanoparticles for drug delivery, imaging, and therapeutic purposes. Furthermore, nanostructures are said to aid in the transport of scarce water-soluble medications to their target area, as well as reducing drug tarnishing in the gastrointestinal region. Because nanodrugs have conventional absorptive endocytosis uptake mechanisms, they have a higher oral bioavailability.

\section{Nano based drug delivery systems:}

There have been significant advancements in the field of delivery systems to transfer therapeutic agents or natural-based active chemicals to their target region for the treatment of a variety of ailments recently . Although a lot of drug delivery systems have been successfully implemented in recent years, there are still some issues to be addressed and sophisticated technologies to be created in order to successfully transport medications to their target sites. As a result, nano-based drug delivery systems are currently being investigated in order to promote the development of a more advanced drug delivery system.

Nanomedicine is a branch of medicine that employs nanoscale materials, such as biocompatible nanoparticles and nanorobots, for a variety of applications, including diagnosis, delivery, sensing , and actuation in a living body. Drugs with very low solubility have a variety of biopharmaceutical delivery issues, including limited bioaccess after oral intake, lower diffusion capacity into the outer membrane, higher intravenous dosage requirements, and undesirable side effects prior to the traditional formulated vaccination process. All of these constraints, however, could be solved by incorporating nanotechnology into the medication delivery process. 
Because of its potential advantages, such as the ability to modify properties like solubility, drug release profiles, diffusivity, bioavailability, and immunogenicity, drug design at the nanoscale has been extensively studied and is by far the most advanced technology in the field of nanoparticle applications. As a result, more convenient administration routes may be developed, with lower toxicity, fewer adverse effects, improved biodistribution, and a longer drug life cycle. Engineered drug delivery systems are either targeted to a specific location or are designed to release therapeutic substances in a regulated manner to a specific region. Their formation is based on selfassembly, in which building units spontaneously create well-defined shapes or patterns. They must also overcome obstacles such as opsonization and sequestration by the mononuclear phagocyte system . Nanostructures can distribute medications in one of two ways: passive or self-delivery. Drugs are primarily incorporated into the inner cavity of the structure via the hydrophobic action in the former. Because the pharmaceuticals are contained in a hydrophobic environment, the intended amount of the drug is released when the nanostructure materials are targeted to specific places. The medications intended for release, on the other hand, are immediately conjugated to the carrier nanostructure material for convenient delivery. The timing of release is critical in this strategy because the drug does not reach the target site and dissociates from the carrier quickly, and its bioactivity and efficacy are reduced if it is released from its nanocarrier system at the wrong moment. Another important component is drug targeting, which uses nanomaterials or nanoformulations as drug delivery devices and is divided into active and passive categories. Antibodies and peptides are combined with drug delivery systems in active targeting to bind them to receptor structures expressed at the target site. The produced drug carrier complex circulates through the circulation and is guided to the target site by affinity or binding, which is regulated by variables such as $\mathrm{pH}$, temperature, molecular site, and shape. The receptors on cell membranes, lipid components of the cell membrane, and antigens or proteins on cell surfaces are the principal targets in the body. The majority of nanotechnology-mediated medication delivery systems are currently aimed towards cancer treatment and prevention.

\section{Drug designing and mechanism of action:}

Numerous therapeutic procedures have been presented and traditional clinical diagnostic methods have been examined to boost drug specificity and diagnostic accuracy, thanks to the advancement of nanomedicine and the advancement of drug discovery/design and drug delivery systems. New drug administration methods, for example, are being investigated, with a focus on assuring targeted action in specific locations, lowering toxicity and boosting bioavailability in the organism .

Drug designing, in this context, has been a promising aspect that marks the discovery of innovative lead medications based on biological target information. The advancement of experimental procedures for the categorization and purification of proteins, peptides, and biological targets, as well as advances in computer sciences, are critical for the sector's growth and development . In addition, there are multiple research and reviews in this area that focus on the rational design of various compounds and demonstrate the necessity of understanding various drug release mechanisms [68]. Furthermore, natural compounds can be used as inspiration for drug development with desirable physicochemical features.

In recent years, drug delivery technologies have also become more important. Such systems are simple to create and capable of encouraging the controlled release of active chemicals in the body. Chen et al. , for example, offered an intriguing evaluation of nanocarriers for imaging and sensory applications, as well as the therapeutic effects of these systems. Pelaz 
et al. also offered an up-to-date summary of many nanocarrier uses in nanomedicine, as well as fresh potential and difficulties for this field.

Each of these drug delivery systems has its unique chemical, physical, and morphological features, and may have affinity for different drug polarities via chemical or physical interactions (e.g., covalent bonds and hydrogen bonds) (e.g., electrostatic and van der Waals interactions). Mattos et al. showed that neem bark extract-grafted biogenic silica nanoparticles had a lower release profile (chemical interactions) than neem bark extract-loaded biogenic silica nanoparticles. As a result, all of these characteristics have an impact on the interaction of nanocarriers with biological systems, as well as the active ingredient release kinetics in the body. Furthermore, Sethi et al. developed a crosslinkable lipid shell (CLS) containing docetaxel and wortmannin as archetypal drugs for manipulating drug discharge kinetics, and then investigated its discharge profile, which was found to be altered in both in vivo and in vitro circumstances. Other factors to consider include the nanocarriers' composition (e.g., organic, inorganic, and hybrid materials) and the way pharmaceuticals are attached to them (e.g., core-shell system or matrix system). Several investigations on drug release mechanisms in nanocarriers have been undertaken collectively. As shown in Fig. 2 , diffusion, solvent, chemical reaction, and stimuli-controlled release are some of the mechanisms that can represent drug release in nanocarriers. Kamaly et al. conducted a comprehensive evaluation of controlled-release systems, focusing on experiments involving drug release from polymeric nanocarriers.

\section{Mechanisms for controlled release of drugs using different types of nanocarriers :}

Despite the fact that there are several nanocarriers with different drug release profiles, strategies are currently being developed to improve the specificity of nanostructures to target regions of the organism and to reduce immunogenicity by coating or chemical functionalization with a variety of substances, including polymers, natural polysaccharides , antibodies, cell-membrane, and cell-membrane ]. These ligand-modified nanocarriers have been used to pass through the cell membrane and allow a programmed drug delivery in a specific environment in some cases where drugs do not display binding and affinity with a specific target or do not cross certain barriers (e.g. blood-brain barrier or bloodcerebrospinal fluid barrier). For example, hyaluronic acid (a polysaccharide found in the extracellular matrix) has been used as a ligand-appended in several nanocarriers, with promising results in boosting antitumor action against melanoma stem-like cells , breast cancer cells, pulmonary adenocarcinoma cells , as well as facilitating intravitreal drug delivery for retinal gene therapy and reducing the toxicity of intra. The creation of ligand-appended drug delivery systems, on the other hand, is time-consuming, and numerous targeting designs must be completed beforehand, taking into account physiological aspects such as blood flow, disease condition, and tissue architecture . Furthermore, few studies have been conducted to assess the interaction of ligandappended nanocarriers with cell membranes, and their uptake process remains unknown. Furthermore, it is well known that nanoparticles are taken up by cells via phagocytic or non-phagocytic pathways (e.g., clathrin-mediated endocytosis, caveolae-mediated endocytosis, and others) . However, due to some unique physicochemical characteristics of each delivery system, standardising the mechanism of action/interaction of these systems in the cGMP environment has proven difficult. In a review, Salatin and Khosroushahi discussed the major endocytosis pathways involved in the cellular uptake of polysaccharide nanoparticles carrying active chemicals.

Stimuli-responsive nanocarriers, on the other hand, have demonstrated the ability to control the release profile of drugs (as a triggered release) using external factors such as ultrasound, heat, magnetism, light , 
$\mathrm{pH}$, and ionic strength , allowing for better targeting and dosage control (Fig. 2). For example, by applying an external magnetic field to superparamagnetic iron oxide nanoparticles, polymeric nanocarriers or lipids are used to drive a controlled release system. Ulbrich et al. also reviewed current advances in drug delivery methods, focusing on polymeric and magnetic nanoparticles, as well as the effect of covalently or noncovalently linked pharmaceuticals for cancer cure . In addition, Au/Fe3O4@polymer nanoparticles have been created for application in NIR-triggered chemo-photothermal treatment. As a result, hybrid nanocarriers are currently one of the most promising tools for nanomedicine, as they combine the features of many systems into a single system, resulting in materials that perform better in both therapeutic and diagnostic applications (i.e., theranostic systems). Despite this, little is known about the true mechanisms of action and toxicity of drug delivery systems, opening up new research opportunities. Furthermore, research into the manufacturing of nanocarriers based on ecologically friendly chemical processes employing plant extracts and microorganisms has intensified.

\section{Nanoparticles used in drug delivery system}

There are numerous biopolymeric materials that are utilized in the drug delivery systems. These materials and their properties are discussed below.

\section{Solid lipid nanoparticles (SLNs)}

For many years, oil-in-water $(\mathrm{O} / \mathrm{W})$ emulsions, liposomes, microparticles, and nanoparticles based on synthetic polymers or natural macromolecules have all been researched. Solid lipid nanoparticles (SLN), which were initially created in 1991, have supplanted traditional colloidal carriers such as emulsions, liposomes, and polymeric micro- and nanoparticles. SLN combines the advantages of traditional systems while avoiding some of its major shortcomings. The present state of the art in terms of SLN production techniques, drug integration, loading capacity, and drug release, with a focus on drug release mechanisms, is examined in this study. The status of excipients, toxicity/tolerability concerns, sterilisation, and longterm stability, including industrial large-scale production, are also considered as relevant considerations for the introduction of SLN to the pharmaceutical market. The possibility for SLN to be used for various administration channels is discussed. There are a number of well-known reasons behind this, two of which require specific attention: polymer cytotoxicity and the lack of a viable large-scale manufacturing technique. No tests have been done on polymers that have been approved for use as implants.It is also vital to have adequate tolerability in the form of nanoparticles.Being in the nanoscale range and having a size of a few nanometers. Artemisinin, the key ingredient in the Chinese herb Artemisia annua L., and its derivatives have become the most widely used antimalarial medications in recent years. Artemisinins' medicinal efficacy is particularly appealing because Multidrug-resistant strains are becoming more common. Dihydroartemisinin, for example, is an artemisinin derivative artemethe (Dhingra et al., 2000; Wiesner et al., 2003)[3]. ART, a dihydroartemisinin ethyl ether derivative, has been presented as a new semisynthetic antimalarial medication. (Brossi et al., 1988). Chitosan possesses mucoadhesive properties and can be used to work in very tight epithelial junctions.Thus, chitosan-based nanomaterials are widely used for continued drug release systems for various types of epithelia, including buccal , intestinal, nasal, eye and pulmonary . Silva et al. prepared and evaluated the efficacy of a $0.75 \% \mathrm{w} / \mathrm{w}$ isotonic solution of hydroxypropyl methylcellulose (HPMC) containing chitosan/sodium tripolyphosphate/hyaluronic acid nanoparticles to deliver the antibiotic ceftazidime to the eye. The rheological synergism parameter was calculated by calculating the viscosity of the nanoparticles in contact with mucin in different mass proportions. A minimum viscosity was observed when chitosan 
nanoparticles were placed in contact with mucin. However, the nanoparticles presented mucoadhesion which resulted in good interaction with the ocular mucosa and prolonged release of the antibiotic, and therefore, the nanoparticles can enhance the life span of the drug in the eyes. The nanoparticles did not show cytotoxicity for two cell lines tested (ARPE-19 and HEK 239T). The nanoparticles were also able to preserve the antibacterial activity, thus making them a promising formulations for the administration of ocular drugs with improved mucoadhesive properties.

Pistone et al. prepared nanoparticles of chitosan, alginate and pectin as potential candidates for the administration of drugs into the oral cavity. The biocompatibility of the formulations was estimated based on the solubility of the nanoparticles in a salivary environment and its cytotoxicity potential was estimated in an oral cell line. Alginate nanoparticles were the most unwavering in the artificial saliva for at least $2 \mathrm{~h}$, whereas pectin and especially chitosan nanoparticles were unstable. However, the chitosan nanoparticles were the most cyto-competitive, whereas alginate and pectin nanoparticles showed cytotoxicity under all tested conditions (concentration and time). The presence of Zn2+ (cross-linking agent) may be the cause of the observed cytotoxicity. Each formulation presented advantage and limitations for release into the oral cavity, thus necessitating their further refinement.

In addition, Liu et al. prepared nanoparticles of carboxymethyl chitosan for the release of intra-nasal carbamazepine (CBZ) to bypass the blood-brain barrier membrane, thus increasing the amount of the medication in the brain and refining the treatment efficacy, thereby reducing the systemic drug exposure. The nanoparticles had a mean diameter of $218.76 \pm 2.41 \mathrm{~nm}$, encapsulation efficiency of $80 \%$ and drug loading of $35 \%$. Concentrations of CBZ remained higher $(\mathrm{P}<0.05)$ in the brain than the plasma over $240 \mathrm{~min}$.

In another example, Jain and Jain investigated the discharge profile of 5-fluorouracil (5-FU) from hyaluronic acid-coated chitosan nanoparticles into the gut, via oral administration. Release assays in conditions mimicking the transit from the stomach to the colon indicated the release profile of 5-FU which was protected against discharge in the stomach and small intestine. Also, the high local concentration of drugs would be able to increase the exposure time and thus, enhance the capacity for antitumor efficacy and decrease the systemic toxicity in the treatment of colon cancer.

\section{Silver Nanoparticle}

The development of a dependable and environmentally acceptable approach for the synthesis of metallic nanoparticles is a critical milestone in the field of nanotechnology application. Natural processes, such as the usage of biological systems, are one approach for achieving this goal. We used Aspergillus fumigatus to explore extracellular production of silver nanoparticles. The plasmon absorbance of silver nanoparticles was detected in the UV-visible spectrum of an aqueous media containing silver ions, with a peak at $420 \mathrm{~nm}$. The development of well-dispersed silver nanoparticles in the range of 5-25 nm was seen in a transmission electron microscopy (TEM) micrograph. The silver nanoparticles' X-ray diffraction (XRD) spectrum revealed two values matching to the silver nanocrystals. The extracellular and rapid reduction process could lead to the creation of a simple bioprocess for the manufacture of silver nanoparticles.

\section{Alginate}

Another biopolymeric material that has been used as a drug delivery is alginate. This biopolymer presents final carboxyl groups, being classified as anionic mucoadhesive polymer and presents greater mucoadhesive strength when compared with cationic and neutral polymers . Patil and Devarajan developed insulin-containing alginate nanoparticles with nicotinamide as a permeation agent in order to lower the serum glucose levels and raise serum insulin levels 
in diabetic rats. Nanoparticles administered sublingually (5 IU/kg) in the presence of nicotinamide showed high availability pharmacology $(>100 \%)$ and bioavailability $(>80 \%)$. The fact that NPs are promising carriers of insulin via the sublingual route have been proved in case of the streptozotocininduced diabetic mouse model by achieving a pharmacological high potential of $20.2 \%$ and bioavailability of $24.1 \%$ compared to the subcutaneous injection at $1 \mathrm{IU} / \mathrm{kg}$.

Also, Haque et al. prepared alginate nanoparticles to release venlafaxine (VLF) via intranasal for treatment of depression. The higher blood/brain ratios of the VLF concentration to the alginate nanoparticles administered intra-nasally when compared to the intranasal VLF and VLF solution intravenously indicated the superiority of the nano-formulation in directly transporting the VLF to the brain. In this way, these nanoparticles are promising for the treatment of depression. In another example, Román et al. prepared alginate microcapsules containing epidermal growth factor bound on its exterior part to target the non-small cell lung cancer cells. Cisplatin (carcinogen drug) was also loaded in the nanoparticles. The addition of EGF significantly increased specificity of carrier systems and presented kinetics of cell death (H460-lung cancer strain) faster than the free drug.

In addition, Garrait et al. prepared nanoparticles of chitosan containing Amaranth red (AR) and subsequently microencapsulated these nanoparticles in alginate microparticles and studied the release kinetics of this new system in simulated gastric and intestinal fluids. The microparticles had a mean diameter of $285 \mu \mathrm{m}$ with a homogeneous distribution; it was observed that there was a release of less than $5 \%$ of the AR contained in the systems in the gastric $\mathrm{pH}$ conditions, whereas the discharge was fast and comprehensive in the intestinal $\mathrm{pH}$ conditions. Thus, the carrier showed promise to protect molecules for intestinal release after oral administration.
Costa et al. prepared chitosan-coated alginate nanoparticles to enhance the permeation of daptomycin into the ocular epithelium aiming for an antibacterial effect. In vitro permeability was assessed using ocular epithelial cell culture models. The antimicrobial activity of nanoencapsulated daptomycin showed potential over the pathogens engaged in bacterial endophthalmitis. Also, the ocular permeability studies demonstrated that with $4 \mathrm{~h}$ of treatment from 9 to $12 \%$ in total of daptomycin encapsulated in chitosan/alginate nanoparticles, these were able to cross the HCE and ARPE-19 cells. These results indicated that with this system an increasing in the drug retention in the ocular epithelium has occurred.

\section{Xanthan gum}

Xanthan gum (XG) is a high molecular weight heteropolysaccharide produced by Xanthomonas campestris. It is a polyanionic polysaccharide and has good bioadhesive properties. Because it is considered non-toxic and non-irritating, xanthan gum is widely used as a pharmaceutical excipient.

Laffleur and Michalek have prepared a carrier composed of xanthan gum thiolated with L-cysteine to release tannin in the buccal mucosa to treat sialorrhea. Thiolation of xanthan gum resulted in increased adhesion on the buccal mucosa when compared to native xanthan gum. In addition, xanthan gum thiolate has a higher uptake of saliva whereas tannic acid ad-string and dry the oral mucosa. In this way, this system would be an efficient way of reducing the salivary flow of patients with sialorrhea. Angiogenesis is an important feature in regeneration of soft tissues.

Huang et al. prepared injectable hydrogels composed of aldehyde-modified xanthan and carboxymethylmodified chitosan containing potent angiogenic factor (antivascular endothelial growth factor, VEGF) to improve abdominal wall reconstruction. The hydrogel presented release properties mainly in tissues like digestive tract and open wounds. The hydrogel 
containing VEGF was able to accelerate the angiogenesis process and rebuild the abdominal wall. Menzel et al. [127] studied a new excipient aiming the use as nasal release system. Xanthan gum was used as a major polymer in which the-((2-amino-2carboxyethyl) disulfanyl) nicotinic acid (Cys-MNA) was coupled. Characteristics, such as amount of the associated binder, mucoadhesive properties and stability against degradation, were analyzed in the resulting conjugate. Each gram of polymer was ligated with $252.52 \pm 20.54 \mu \mathrm{mol}$ of the binder. The mucoadhesion of the grafted polymer was 1.7 fold greater than that of thiolated xanthan and 2.5 fold greater than, that of native xanthan. In addition, the frequency of ciliary beating of nasal epithelial cells was poorly affected and was reversible only upon the removal of the polymer from the mucosa.

\section{TiO2 nanotubes}

In materials research, $\mathrm{TiO} 2$ is one of the most investigated substances.

It's employed in photocatalysis, dye-sensitized solar cells, and biomedical devices because of its unique features. In The feasibility of growing highly ordered arrays was first demonstrated in 1999.using a simple but optimised electrochemical anodization of a titanium metal sheet to produce $\mathrm{TiO} 2$ nanotubes. This discovery sparked a flurry of research into the growth, modification, characteristics, and uses of onedimensional nanostructures.[6] This is a review of Attempts to cover all of these features, as well as the underlying principles and concepts.key functional properties of $\mathrm{TiO} 2$ in a thorough manner, as well as outlines where the field might go in the future. , the drug Author to whom correspondence should be addressed.The majority of carriers are employed in human medications.

(for example, antitumor21 and anticancer22 medicines) while the fabrication of titania nanotube compositions Veterinary medication and its controlled release property have never been made public.

\section{Cellulose}

Cellulose and its derivatives are extensively utilized in the drug delivery systems basically for modification of the solubility and gelation of the drugs that resulted in the control of the release profile of the same. Elseoud et al.investigated the utilization of cellulose nanocrystals and chitosan nanoparticles for the oral releasing of repaglinide (an anti-hyperglycemicRPG). The chitosan nanoparticles showed a mean size distribution of $197 \mathrm{~nm}$ while the hybrid nanoparticles of chitosan and cellulose nanocrystals containing RPG. Chitosan hybrid nanoparticles and oxidized cellulose nanocrystals containing RPG had a mean diameter of 251-310 nm. The presence of the hydrogen bonds between the cellulose nanocrystals and the drug, resulted in sustained release of the same, and subsequently the nanoparticles made with oxidized cellulose nanocrystals presented lower release when compared to the nanoparticles produced with native cellulose nanocrystals.

Agarwal et al. have developed a drug targeting mechanism which is based on the conjugation of calcium alginate beads with carboxymethylcellulose (CMC) loaded 5-fluoroacyl (5-FU) and is targeted to the colon. The beads with lower CMC proportions presented greater swelling and muco-adhesiveness in the simulated colonic environment. With existence of colonic enzymes there was a $90 \%$ release of $5-\mathrm{FU}$ encapsulated in the beads. Hansen et al. investigated four cellulose derivatives, including, meteylcellulose, hydroxypropyl methylcellulose, sodium carboxymethylcellulose and cationic hydroxyethyl cellulose for application in drug release into the nasal mucosa. The association of these cellulose derivatives with an additional excipient, was also evaluated. The drug model employed in this process was acyclovir. The viability of the polymers as excipients for nasal release applications was also scrutinized for its ciliary beat frequency $(\mathrm{CBF})$ and its infusion through the tissue system of the nostril cavity. An increase in thermally induced viscosity was observed when the 
cellulose derivatives were mixed with polymer graft copolymer. Further an increased permeation of acyclovir into the nasal mucosa was detected when it was combined with cationic hydroxyethylcellulose. None of the cellulose derivatives caused negative effects on tissues and cells of the nasal mucosa, as assessed by CBF.

\section{Nanostructured Lipid Carriers}

Professor R.H. Müller (Germany) and Professor M. Gasco (Italy) began researching the possibility of a new nanoparticle-based formulation dubbed solid lipid nanoparticles in the early 1990s (SLN).Their lipid-based formulation has several advantages, including the ability to avoid using an organic solvent during the manufacturing process, as opposed to existing organic nanoparticles (e.g. PLGAnanoparticles), and a high level of stability in vivo, as they remained solid at body temperature. They were an alternative not just to organic nanoparticles but also to earlier lipid-based formulations because of this feature (e.g. liposomes)[10]. However, one significant flaw appeared to jeopardise the formulation's future applicability: the low drug loading. Further research into the formulation was beneficial.The SLN is becoming better. The addition of a liquid lipid to the nanoparticle's solid matrix was found to enhance the number of defects in the core solid matrix, allowing for the integration of more medication while maintaining the nanocarriers' physical stability. As nanostructured lipid carriers, this new unstructuredmatrix SLN was created (NLC).

\section{Liposomes}

They were discovered by Alec Bangham in 1960 . Liposomes are used in the pharmaceutical and cosmetics industry for the transportation of diverse molecules and are among the most studied carrier system for drug delivery. Liposomes are an engrained formulation strategy to improve the drug delivery. They are vesicles of spherical form composed of phospholipids and steroids usually in the 50-450 nm size range. These are considered as a better drug delivery vehicles since their membrane structure is analogous to the cell membranes and because they facilitate incorporation of drugs in them. It has also been proved that they make therapeutic compounds stable, improve their biodistribution, can be used with hydrophilic and hydrophobic drugs and are also biocompatible and biodegradable. Liposomes are divided into four types: (1) conventional type liposomes: these consists of a lipid bilayer which can make either anionic, cationic, or neutral cholesterol and phospholipids, which surrounds an aqueous core material. In this case, both the lipid bilayer and the aqueous space can be filled with hydrophobic or hydrophilic materials, respectively. (2) PEGylated types: polyethylene glycol (PEG) is incorporated to the surface of liposome to achieve steric equilibrium, (3) ligand-targeted type: ligands like antibodies, carbohydrates and peptides, are linked to the surface of the liposome or to the end of previously attached PEG chains and (4) theranostic liposome type: it is an amalgamation kind of the previous three types of liposomes and generally consists of a nanoparticle along with a targeting, imaging and a therapeutic element .

The typical synthesis procedure for liposomes are as follows, thin layer hydration, mechanical agitation, solvent evaporation, solvent injection and the surfactant solubilization . One aspect to point out on liposomes is that the drugs that are trapped within them are not bioavailable until they are released. Therefore, their accumulation in particular sites is very important to increase drug bioavailability within the therapeutic window at the right rates and times. Drug loading in liposomes is attained by active (drug encapsulated after liposome formation) and passive (drug encapsulated during liposome formation) approaches . Hydrophilic drugs such as ampicillin and, 5-fluoro-deoxyuridine are typically confined in the aqueous core of the liposome and thus, their encapsulation does not depend on any modification in 
the drug/lipid ratio. However, the hydrophobic ones such as Amphotericin B, Indomethacin were found in the acyl hydrocarbon chain of the liposome and thus their engulfing are subjected to the characteristics of the acyl chain . Among the passive loading approaches the mechanical and the solvent dispersion method as well as the detergent removal method can be mentioned .

There are obstacles with the use of liposomes for drug delivery purposes in the form of the RES (reticuloendothelial system), opsonization and immunogenicity although there are factors like enhanced permeability and EPR (retention effect) that can be utilized in order to boost the drug delivery efficiency of the liposomes. Once liposomes get into the body, they run into opsonins and high density lipoproteins (HDLs) and low density lipoproteins (LDLs) while circulating in the bloodstream by themselves. Opsonins (immunoglobulins and fibronectin, for example) assist RES on recognizing and eliminating liposomes. HDLs and LDLs have interactions with liposomes and decrease their stability. Liposomes tends to gather more in the sites like the liver and the spleen, this is an advantage because then a high concentration of liposomes can help treat pathogenic diseases, although in the case of cancers this can lead to a delay in the removal of lipophilic anticancer drugs. This is the reason why as mentioned at the beginning, different types of liposomes have been developed, in this case PEGylated ones. Dimov et al. reported an incessant procedure of flow system for the synthesis, functionalization and cleansing of liposomes. This research consists of vesicles under $300 \mathrm{~nm}$ in a labon-chip that are useful and potential candidates for cost-intensive drugs or protein encapsulation development. This is very important because costs of production also determine whether or not a specific drug can be commercialized. Liposome-based systems have now been permitted by the FDA.

\section{Polypeptide Nanoparticles}

Biopolymers inspired by human elastin are known as elastin-like polypeptides (ELPs). They are useful materials for stimulus-responsive applications in biological contexts because of their reduced critical solution temperature phase transition behaviour and biocompatibility. The sequence and size of ELPs can be precisely defined thanks to their genetically encoded design and recombinant production. Synthetic polymers can't match the accuracy with which these design parameters regulate the ELP's structure and function. ELPs have been widely employed for drug administration in a number of forms, including soluble macromolecular carriers, self-assembled nanoparticles, cross-linked microparticles, and thermally coacervated depots, due to their properties. These ELP systems have been utilised to deliver biologic therapies, radionuclides, and small molecule medicines to a range of anatomical regions for diseases such as cancer, type 2 diabetes, osteoarthritis, and neuroinflammation. MDR (multi-drug resistance) is a significant impediment to cancer therapy success. MDR is primarily responsible for tumour recurrence and metastasis in breast cancer, making treatment more challenging. The MDR is a very well-understood molecular mechanism, which is mostly attributed to the over-expression of certain genes.P-glycoprotein is a kind of glycoprotein (P-gp).

\section{Description of Phytochemicals}

Polyphenols, favonoids, steroidal saponins, organosulphur compounds, and vitamins are examples of phytochemicals, which are secondary metabolites of plants and include a vast variety of chemical entities. They play a crucial role in plant growth by participating in physiological processes such as reproduction, symbiotic relationships, and interactions with other organisms and the environment. Despite the fact that most of these chemicals are produced naturally, their synthesis can 
be boosted under stress circumstances, depending on the growth environment and the stressor. Plants have long been regarded as a source of food and therapeutic substances : up to 200 species are classified as medicinal plants, and approximately $25 \%$ of medicines are derived from plants [21]. Carotenoids are potent antioxidants that are responsible for many of the red, orange, and yellow hues found in flowers, foliage, and fruits. Because they are abundant in fruits and vegetables, they are readily available. The subclasses of flavonoids are favonols, favones, favanones, favan-3-ols, isofavones, and anthocyanidins. Researchers have been drawn to them because of their beneficial effects on a variety of disorders, as detailed in this review. For example, quercetin and anthocyanins have been shown to be effective in reducing malignant cell growth rates, inducing carcinogen metabolism, lowering tissue inflammation parameters, and blocking angiogenesis. Terpenoids are a wide group of secondary metabolites found in plants. Monoterpenes, sesquiterpenes, and diterpenes isolated from aromatic plants have significant antioxidant activity, according to in vitro tests. The alkaloids vindoline, vindolidine, vindolicine, and vindolinine, isolated from Catharanthus roseus leaves, have been shown to have hypoglycemic and antioxidant action [40]. Natural chemicals, on the other hand, are now being investigated for the treatment of a variety of ailments, including cancer, diabetes, cardiovascular, inflammatory, and microbiological diseases. This is due to the fact that natural medications have distinct advantages such as reduced toxicity and side effects, low cost, and high therapeutic potential. As a result, adopting innovative drug delivery technologies to target medications to specific body areas could be a viable solution to these problems . As a result, phytochemicals in combination with NPs play an important role in enhanced medicine/drug formulations, targeted arena, and controlled drug release and delivery with great effectiveness.

\section{Bioavailability of Phytochemicals}

Soyasaponin. When performing in vivo tests with animals and humans, soyasaponin has an extremely poor bioavailability (Kang et al., 2010). However, potential metabolites of soyasaponin have been discovered in in vitro and in vivo investigations, even if they are discovered many days after consumption (Kang et al., 2010). Soyasapogenol B, which is released into faeces in human in vivo studies, is one of the metabolites. However, in vitro evidence using fresh faecal microbiota suggests that the metabolism is more likely attributable to bacteria in the colon.

Lignan. After intake of lignans, low lignan bioavailability is restored in human plasma (Kang et al., 2010). It's noteworthy to note that lignan is quickly absorbed into the bloodstream after consumption. Secoisolariciresinol diglucoside and its aglycones secoisolariciresinol and matairesinol are the only ones for which data is available. According to research, intestinal bacteria metabolise at least $40 \%$ of ingested lignans, and their metabolites may be identified in the plasma.

Phytosterol. After intake, human plasma shows low phytosterol bioavailability. In vivo, a tiny quantity of phytosterol (0.6-7.5\%) is carried via stomach epithelial cells. Although phytosterol and cholesterol are chemically identical, cholesterol is absorbed at a considerably greater rate than phytosterol. This is due to side chain variations, such as the existence of a double bond and the presence of an ethyl/methyl group in C24, which promotes hydrophobicity but decreases absorption.

Phytate. After intake, phytate bioavailability in human plasma is minimal. After consumption, plasma myo-[inositol-2-H3(N)]hexakisphosphate in humans is dose-dependent, reaching only 3-5 times that of a diet low in myo-[inositol-2-H3(N)]hexakisphosphate. A rat research revealed that ingested phytate is 
swiftly transported in its original food molecule forms into organs such the brain, kidneys, liver, and bone. When compared to the average of tissues, the largest amount is seen in the brain, which is 10 times higher (Kang et al., 2010).

Caffeine. Caco-2 monolayers are used to simulate absorption of a pure chemical in the gut, using pharmacological principles. The unaltered caffeine was transferred across epithelial cells in the simulated transit technique. Caffeine is delivered straight to the basolateral compartment without causing damage to the tight connections. Over the course of the bioassay, this transport occurs preferentially in the apical to basolateral direction (240 $\mathrm{min})$. Caffeine was transferred from apical to basolateral by enterocytes, presumably without generating an equilibrium condition. Caffeine uptake was fast, and basolateral secretion may have needed a little quantity of caffeine to be kept intracellularly.

Catechin. Catechin is kept in the apical compartment at roughly one-third of its original quantity (86.8 $\mathrm{nmol}$ ) according to the simulated transit technique, and this level is maintained throughout the trial. However, examination of the basolateral compartment revealed that the quantity of translocated catechin was not equal. Most basolateral samples, on the other hand, have relatively little catechin. The apical catechin concentration was decreased to $39 \mathrm{nmol}$ after 22 hours in the static apical solution technique, but there was no evidence of transported catechin in the basolateral compartment. Based on apical losses, there may have been some catechin metabolism in the current study, which necessitates additional research to discover potential catechin metabolites.

For all time periods, lycopene is neither transported nor chemically altered during bioassay utilizing all three bioassay techniques. Lycopene appears to be unable to pass through monolayers via paracellular or transcellular pathways due to its hydrophobicity and unfavourable molecular geometry. The reduction in TEER values for all monolayers, which was not followed by lycopene translocation from the apical solutions into the basolateral compartment, corroborated this. The apical lycopene does not vanish in the transit model in the current investigation. The presences of other carotenoids, lipid status, and plasma antioxidant capacity have all been demonstrated to impact lycopene absorption (Bohm \& Bitsch, 1999). However, according to another study, plasma lycopene levels after eating cherry tomatoes are insignificantly different from the plasma baseline (Bugianesi et al., 2004).

TABLE. I : LIST OF PHYTOCHEMICALS

\begin{tabular}{|c|l|l|l|l|l|}
\hline $\begin{array}{l}\text { SL. } \\
\text { NO }\end{array}$ & Name of the compound & $\begin{array}{l}\text { Molecular } \\
\text { formula }\end{array}$ & $\begin{array}{l}\text { Molecula } \\
\mathbf{r} \\
\text { Weight } \\
(\mathbf{g} / \mathbf{m o l})\end{array}$ & $\begin{array}{l}\text { Retention } \\
\text { Time }\end{array}$ & $\begin{array}{l}\text { Compound } \\
\text { nature }\end{array}$ \\
\hline 1. & Glycerol tripropanoate & $\mathrm{C}_{12} \mathrm{H}_{20} \mathrm{O}_{6}$ & 260.1241 & 6.408 & Triglyceride. \\
\hline 2. & Azelaic acid & $\mathrm{C}_{9} \mathrm{H}_{16} \mathrm{O}_{4}$ & 188.1038 & 6.854 & $\begin{array}{l}\text { saturated } \\
\text { dicarboxylic acid. }\end{array}$ \\
\hline 3. & methyl (+)-7-isojasmonate & $\mathrm{C}_{13} \mathrm{H}_{20} \mathrm{O}_{3}$ & 224.1397 & 7.406 & sesquiterpenes \\
\hline 4. & 6-Demethoxycapillarisin & $\mathrm{C}_{15} \mathrm{H}_{10} \mathrm{O}_{6}$ & 286.0459 & 8.287 & Glycoside. \\
\hline 5. & Petroselinic acid & $\mathrm{C}_{18} \mathrm{H}_{34} \mathrm{O}_{2}$ & 282.2535 & 18.878 & Fatty acids. \\
\hline 6. & L-isoleucine and L-proline & $\mathrm{C}_{11} \mathrm{H}_{20} \mathrm{~N}_{2} \mathrm{O}_{3}$ & 228.1471 & 1.492 & Amino acid. \\
\hline
\end{tabular}




\begin{tabular}{|c|c|c|c|c|c|}
\hline 7. & Betamethasone & $\mathrm{C}_{22} \mathrm{H}_{29} \mathrm{FO}_{5}$ & 392.201 & 4.459 & steroids \\
\hline 8. & Senampeline A & $\mathrm{C}_{25} \mathrm{H}_{31} \mathrm{NO}_{8}$ & 473.2115 & 4.459 & Alkaloids \\
\hline 9. & $\begin{array}{l}\text { 3-Hydroxy-4- } \\
\text { isopropylbenzyl alcohol 3- } \\
\text { glucoside }\end{array}$ & $\mathrm{C}_{16} \mathrm{H}_{24} \mathrm{O}_{7}$ & 328.1514 & 4.669 & $\begin{array}{l}\text { Terpene } \\
\text { glycosides. }\end{array}$ \\
\hline 10. & Flurandrenolide & $\mathrm{C}_{24} \mathrm{H}_{33} \mathrm{FO}_{6}$ & 436.2266 & 4.67 & Steroids. \\
\hline 11. & Istamycin C1 & $\mathrm{C}_{19} \mathrm{H}_{37} \mathrm{~N}_{5} \mathrm{O}_{6}$ & 431.2719 & 4.801 & Amino glycoside. \\
\hline 12. & Kolanone & $\mathrm{C}_{33} \mathrm{H}_{42} \mathrm{O}_{4}$ & 502.2975 & 5.287 & Monoterpenoid. \\
\hline 13. & S-Japonin & $\mathrm{C}_{19} \mathrm{H}_{28} \mathrm{O}_{3} \mathrm{~S}$ & 336.1783 & 6.024 & Sesquiterpenoids. \\
\hline 14. & $\begin{array}{l}\text { 10-Deoxygeniposide } \\
\text { tetraacetate }\end{array}$ & $\mathrm{C}_{25} \mathrm{H}_{32} \mathrm{O}_{13}$ & 540.1803 & 6.239 & $\begin{array}{l}\text { Terpene } \\
\text { glycoside. }\end{array}$ \\
\hline 15. & Cinncassiol A & $\mathrm{C}_{20} \mathrm{H}_{30} \mathrm{O}_{7}$ & 382.1963 & 6.522 & Sesquiterpenoid. \\
\hline 16. & N4-Phosphoagmatine. & $\mathrm{C}_{5} \mathrm{H}_{15} \mathrm{~N}_{4} \mathrm{O}_{3} \mathrm{P}$ & 210.0874 & 6.879 & Phosphoramide. \\
\hline 17. & $\begin{array}{l}\text { 6alpha,9-Difluoro11beta- } \\
\text { hydroxypregn-4-ene3,20- } \\
\text { dione }\end{array}$ & $\mathrm{C}_{21} \mathrm{H}_{28} \mathrm{~F}_{2} \mathrm{O}_{3}$ & 366.202 & 7.35 & Steroid. \\
\hline 18. & 6alpha-Carissanol & $\mathrm{C}_{15} \mathrm{H}_{24} \mathrm{O}_{3}$ & 252.1725 & 7.468 & Sesquiterpenoids. \\
\hline
\end{tabular}

Activity study of phytochemicals combined with nanoparticles:

Nanotechnology is a field of research and innovation concerned with building 'things' - generally, materials and devices - on the scale of atoms and molecules. Scientists want to employ nanotechnology to prevent illness, diagnose diseases more rapidly, control disease, and treat disease with target specific drug delivery and fewer adverse effects, as well as develop more suitable prosthesis. Many areas of healthcare research employ nanoparticles and nanostructured surfaces to treat diagnose and control diseases. Now a days new alternative strategies capable of preventing the progressive loss of various diseases are urgently required. Researchers have been particularly interested in phytochemical substances with antioxidative, anti-amyloidogenic, anti-inflammatory, and anti-apoptotic capabilities, which could be useful in the development of therapeutic candidates for a variety of disorders. In this review we have focused on the new nanocarrier strategies, combining them with various phytochemicals to treat diseases. Mahdi Adabi et.al investigated the toxicity of unmodified and tiny nanoparticles is higher than that of modified and bulk materials, respectively through clinical and pre clinical trials. Furthermore, due to the body's immune reaction, spherical nanoparticles are less hazardous than rod nanoparticles (doi: 10.1080/21691401.2016.1178134).

Alexandre

Albanese et.al Studied to correlating the properties of nanomaterials such as size, shape, chemical functionality, surface charge, and composition with biomolecular signaling, biological kinetics, transportation, and toxicity in both cell culture and animal experiments are under way (doi: 10.1146/annurev-bioeng-071811-150124). Sumit Arora et.al presented a summary of nanotoxicology and a concise account of the in vitro toxicity data on nanomaterials. For nanomaterials to move into the applications arena, it is important that nanotoxicology research uncovers and understands how these multiple factors influence their toxicity so that the ensuing undesirable effects can be avoided (doi: 10.1016/j.taap.2011.11.010). Josje H.E. Arts et.al 
reviewed available concepts for the grouping of nanomaterials for human health risk assessment. In their broad conceptual design, the evaluated approaches are consistent or complement each other. All go beyond the determination of mere structureactivity relationships and are founded on different aspects of the nanomaterial life cycle. These include the NM's material properties and biophysical interactions, specific types of use and exposure, uptake and kinetics, and possible early and apical biological effects (doi.org/10.1016/j.yrtph.2014.07.025).
Young Hee Choi et.al provided an updated understanding of nanomedicines with respect to delivery and pharmacokinetics. It describes the process and advantages of the nanomedicines approved by FDA and EMA. New FDA and EMA guidelines will also be discussed. Based on the analysis of recent guidelines and approved nanomedicines, key issues in the future development of nanomedicines will be addressed (doi: 10.1007/s40005-017-0370-4).

TABLE.2 : ACTIVITY STUDY OF PHYTOCHEMICALS WITH RESPECT TO NANOPARTICLES

\begin{tabular}{|c|c|c|c|}
\hline $\begin{array}{ll}\text { Name } & \text { of } \\
\text { Nanoparticles } & \\
\end{array}$ & $\begin{array}{ll}\text { Name } & \text { of } \\
\text { phytochemicals }\end{array}$ & Activity & References \\
\hline Liposomes. & $\begin{array}{l}\text { Cinnamaldehyde and } \\
\text { eugenol. }\end{array}$ & $\begin{array}{l}\text { The activity of eugenol and } \\
\text { cinnamaldehyde bactericidal } \\
\text { concentrations due to their } \\
\text { speed. Inhibition of glucose } \\
\text { uptake or utilisation, as well } \\
\text { as impacts on membrane } \\
\text { permeability, are potential } \\
\text { methods of energy } \\
\text { production inhibition. }\end{array}$ & $\begin{array}{l}\text { Alexander } \quad \text { O. } \\
\text { Gill, 2004. }\end{array}$ \\
\hline $\begin{array}{l}\text { Solid lipid } \\
\text { nanoparticles (SLNs). }\end{array}$ & Berberine. & $\begin{array}{l}\text { Lipogenic genes such as fatty } \\
\text { acid synthase (FAS), } \\
\text { stearoyl-CoA desaturase } \\
\text { (SCD1), and sterol regulatory } \\
\text { element-binding protein 1c } \\
\text { (SREBP1c) were } \\
\text { downregulated in BBR-SLN- } \\
\text { treated livers, whereas } \\
\text { lipolytic gene carnitine } \\
\text { palmitoyltransferase-1 } \\
\text { (CPT1) was increased. }\end{array}$ & Mei Xue, 2015. \\
\hline
\end{tabular}




\begin{tabular}{|c|c|c|c|}
\hline Liposomes. & Vincristine. & $\begin{array}{l}\text { VSLI (vincristine sulfate } \\
\text { liposomal injection) has been } \\
\text { approved for use in patients } \\
\text { with } \\
\text { chromosome (t[9;22]/BCR- } \\
\text { ABL1) (Ph)-negative (Ph-) } \\
\text { disease. Additional clinical } \\
\text { trials of VSLI in adults and } \\
\text { children are ongoing. }\end{array}$ & $\begin{array}{l}\text { Trisha A Soosay } \\
\text { Raj, 2013. }\end{array}$ \\
\hline $\begin{array}{l}\text { Nanostructured lipid } \\
\text { carriers. }\end{array}$ & Tripterine. & $\begin{array}{l}\text { In compared to free tripterine, } \\
\text { CT-NLC significantly } \\
\text { increased anticancer activity } \\
\text { in vitro and in vivo, as well as } \\
\text { cytotoxicity in normal cells. In } \\
\text { conclusion, CT-NLC might be } \\
\text { a viable drug delivery method } \\
\text { for prostate cancer therapy. }\end{array}$ & Ling Yuan, 2013. \\
\hline Chitosan & Artemisinin & $\begin{array}{l}\text { Anticancer Drug loading } \\
\text { capacity is high. In vivo, } \\
\text { thenanoparticle accumulation } \\
\text { was increased in the } 4 \mathrm{~T} 1 \\
\text { breast tumour tissues of } \\
\text { BALB/c mice. }\end{array}$ & Natesan S, 2017. \\
\hline $\begin{array}{l}\text { Pristine C60 fullerene } \\
\text { nanoparticles. }\end{array}$ & Curcumin & $\begin{array}{l}\text { Based on these findings, it can } \\
\text { be concluded that C60, CUR, } \\
\text { and especially the C60 + CUR } \\
\text { combination, have beneficial } \\
\text { properties in maintaining } \\
\text { kidney tissue and function by } \\
\text { effectively preventing } \\
\text { oxidative stress, apoptotic } \\
\text { changes, and cellular changes } \\
\text { in kidney tissue under } \\
\text { hyperglycemia conditions. }\end{array}$ & Ersin Demir, 2020. \\
\hline $\begin{array}{l}\text { Polypeptide } \\
\text { nanoparticles. }\end{array}$ & Genistein (GEN) & $\begin{array}{l}\text { Dox-NPs have the ability to } \\
\text { decrease the negative effects of } \\
\text { free DOX } \cdot \mathrm{HCl} \text { while also } \\
\text { producing a low amount of } \\
\text { intracellular reactive oxygen } \\
\text { species (ROS)-induced } \\
\text { oxidative damage. Genistein, } \\
\text { which inhibits the oxidative }\end{array}$ & Guanyi Wang \\
\hline
\end{tabular}




\begin{tabular}{|c|c|c|c|}
\hline & & $\begin{array}{l}\text { DNA repair enzyme } \\
\text { apurinic/apyrimidinic } \\
\text { endonuclease1 (APE1), can } \\
\text { increase the oxidative damage } \\
\text { caused by ROS in prostate } \\
\text { cancer cells. }\end{array}$ & \\
\hline $\begin{array}{l}\text { graphene oxide-silver } \\
\text { nanoparticle }\end{array}$ & lycopene & $\begin{array}{l}\text { This study is the first to report } \\
\text { that the combination of rGO- } \\
\text { Ag and TSA can cause } \\
\text { potential cytotoxicity and also } \\
\text { induce significantly greater } \\
\text { cell death compared to either } \\
\text { rGO-Ag alone or TSA alone in } \\
\text { SKOV3 cells by various } \\
\text { mechanisms including reactive } \\
\text { oxygen species generation, } \\
\text { mitochondrial dysfunction, } \\
\text { and DNA damage. Therefore, } \\
\text { this combination } \\
\text { chemotherapy could be } \\
\text { possibly used in advanced } \\
\text { cancers that are not suitable } \\
\text { for radiation therapy or } \\
\text { surgical treatment and } \\
\text { facilitate overcoming tumor } \\
\text { resistance and disease } \\
\text { progression. }\end{array}$ & Xi-Feng Zhang, \\
\hline gold nanoparticles & Oridonin & $\begin{array}{l}\text { the proposed multifunctional } \\
\text { GPC1-targeted NPs showed } \\
\text { the selective accumulation in } \\
\text { pancreatic tumors by } \\
\text { NIRF/MRI and targeted } \\
\text { therapy in a preclinical model. } \\
\text { Our results suggest that this } \\
\text { multifunctional theranostic } \\
\text { nanoplatform may open new } \\
\text { avenues for early diagnosis and } \\
\text { targeted treatment of } \\
\text { pancreatic cancer. }\end{array}$ & Qiu W \\
\hline Zinc nanoparticles & pterostilbene & $\begin{array}{lr}\text { an } & \text { anti-inflammatory } \\
\text { triphenolic } & \\
\text { resveratrol and zilbene, }\end{array}$ & $\begin{array}{l}\text { Mina T. Kelleni, } \\
\text { 2021. }\end{array}$ \\
\hline
\end{tabular}




\begin{tabular}{|c|c|c|c|}
\hline & & $\begin{array}{l}\text { management of COVID-19. } \\
\text { The researchers recommend } \\
\text { their administration using a } \\
\text { nano-carrier based drug- } \\
\text { delivery system \& conducting } \\
\text { prompt clinical trials to assess } \\
\text { the potential as a monotherapy } \\
\text { for mild COVID } 19 \text { with a } \\
\text { potential to prevent its } \\
\text { progression to moderate- } \\
\text { severe disease. }\end{array}$ & \\
\hline Platinum Nanoparticles & Retinoic Acid. & $\begin{array}{l}\text { PtNPs may be a potential } \\
\text { preconditioning or adjuvant } \\
\text { compound } \\
\text { chemotherapeutic treatment. } \\
\text { The results of this study } \\
\text { provide a rationale for clinical } \\
\text { evaluation of the combination } \\
\text { of PtNPs andRA for the } \\
\text { treatment of children suffering } \\
\text { from high-risk neuroblastoma. }\end{array}$ & $\begin{array}{l}\text { Sangiliyandi } \\
\text { Gurunathan, } 2020 .\end{array}$ \\
\hline PLGA Nanoparticles & Salidroside & $\begin{array}{l}\text { The Sal-Tam NPs decreased } \\
\text { the tumor volume compared } \\
\text { with saline and showed high } \\
\text { anti-tumor activity. } \\
\text { Enhancement of the } \\
\text { bioavailability of Tam in Sal- } \\
\text { Tam NPs compared with free } \\
\text { Tam in suspension. The } \\
\text { researchers say this could be a } \\
\text { promising approach in breast } \\
\text { cancer therapy. }\end{array}$ & Xuan Yu, 2020. \\
\hline
\end{tabular}

\section{Conclusion and future Prospects}

The increased research in nanomedicine has aided in the reformulation of existing drugs as well as the invention of new ones. Nanotechnology alters medicine's toxicity, solubility, and bioavailability profile, among other things. We have assisted in the translation of various nanomedicine applications into clinical practise over the last two decades, ranging from medical devices to nanopharmaceuticals. However, there is still a long way to go in terms of fully regulating nanomedicines, from developing harmonised definitions across Europe to developing protocols for nanomedicine characterisation, evaluation, and process control. There is still no commonly acknowledged definition for 
nanomedicines, and one may never be possible or practical. The medicinal items come in a wide variety of types and structures, and they've been utilised to treat a wide spectrum of acute and chronic disorders. Furthermore, ongoing research is rapidly leading to the emergence of more sophisticated nanostructured designs, which necessitates a thorough understanding of the pharmacokinetic and pharmacodynamic properties of nanomedicines, which are determined by their chemical composition and physicochemical properties, posing additional regulatory challenges. The European Medicines Agency (EMA) has already established a nanomedicines expert group, which includes people from academia and the European regulatory network. This group's major purpose is to give scientific information regarding nanomedicines so that guidelines can be developed or reviewed. The expert group also assists the EMA in discussions about nanomedicines with international partners. Early advise from regulators for the required data is strongly encouraged for the developer.

Berberine hydrochloride augments the effects of chemotherapy/radiotherapy and has shown strong prospects in cancer treatment due to its interaction with nucleic acid and regulation of cancer cells, as well as induction of autophagy. Vincristine is a paediatric chemotherapeutic drug that is used to treat both hematologic and solid cancers. It's a natural alkaloid that prevents the formation of microtubule structures, causing cell death. Tripterine (TRI), an active monomer found in Tripterygium wilfordii, has pharmacological properties that include antiinflammatory, immunosuppressive, and itanti-tumor effects. In cells, genistein inhibits DNA methyltransferases and has histone modification characteristics. By changing promoter methylation and histone modification, genistein increases the expression of the tumour suppressor genes p21-WAF1 and p16-INK4a. In stomach carcinogenesis, lycopene from red fruits and vegetables possesses potent anticancer properties. ROS have been linked to the development of a number of illnesses, including cancer. ROS cause cell death and encourage tumour spread, angiogenesis, and invasion. Oridonin, a diterpenoid derived from the medicinal herb Rabdosia rubescens, has been shown to have anticancer activity in colon cancer cells 28 , lymphoma cells29, breast cancer cells30, and leukaemia cells31. Oridonin has been shown to trigger apoptosis in a variety of cancers32,33. Salidroside (Sal) is a phenylpropanoid glycoside found in the Rhodiolarosea plant. Sal protected ischemic myocardium by mediating the PI3K/Akt signalling pathway, reducing cardiomyocyte apoptosis, increasing the expression of Bcl-2 and p-Akt proteins, and decreasing the expression of Bax and caspase- 3 proteins. The creation of guidelines for the development and evaluation of nanomedicines is required for a common understanding among many stakeholders in order to approve new and innovative nanomedicines on the pharmaceutical market. This approach must be carried out in tandem with interagency harmonisation initiatives in order to promote sensible scientific and regulatory decisions, as well as financing and market access.

\section{REFERENCES}

[1]. Swamy MK, Sinniah UR. Patchouli (Pogostemon cablin Benth.): botany, agrotechnology and biotechnological aspects. Ind Crops Prod. 2016;87:161-176. doi: 10.1016/j.indcrop.2016.04.032. [CrossRef] [Google Scholar]

[2]. Mohanty SK, Swamy MK, Sinniah UR, Anuradha M. Leptadenia reticulata (Retz.) Wight \& Arn. (Jivanti): botanical, agronomical, phytochemical, pharmacological, and biotechnological aspects. Molecules. 1019;2017:22. [PMC free article] [PubMed] [Google Scholar]

[3]. Rodrigues T, Reker D, Schneider P, Schneider G. Counting on natural products for drug design. Nat Chem. 2016;8:531. doi: 10.1038/nchem.2479. [PubMed] [CrossRef] [Google Scholar] 
[4]. Siddiqui AA, Iram F, Siddiqui S, Sahu K. Role of natural products in drug discovery process. Int J Drug Dev Res. 2014;6(2):172-204. [Google Scholar]

[5]. Beutler JA. Natural products as a foundation for drug discovery. Curr Prot Pharmacol. 2009;46(1):9-11. [PubMed] [Google Scholar]

[6]. Thilakarathna SH, Rupasinghe H. Flavonoid bioavailability and attempts for bioavailability enhancement. Nutrients. 2013;5:3367-3387. doi: 10.3390/nu5093367. [PMC free article] [PubMed] [CrossRef] [Google Scholar]

[7]. Bonifácio BV, da Silva PB, dos Santos Ramos MA, Negri KMS, Bauab TM, Chorilli M. Nanotechnology-based drug delivery systems and herbal medicines: a review. Int $J$ Nanomed. 2014;9:1. doi: 10.2217/nnm.13.186. [PMC free article] [PubMed] [CrossRef] [Google Scholar]

[8]. Watkins R, Wu L, Zhang C, Davis RM, Xu B. Natural product-based nanomedicine: recent advances and issues. Int J Nanomed. 2015;10:6055. [PMC free article] [PubMed] [Google Scholar]

[9]. Martinho N, Damgé C, Reis CP. Recent advances in drug delivery systems. J Biomater Nanobiotechnol. 2011;2:510. doi: 10.4236/jbnb.2011.225062. [CrossRef] [Google Scholar]

[10]. Jahangirian H, Lemraski EG, Webster TJ, RafieeMoghaddam R, Abdollahi Y. A review of drug delivery systems based on nanotechnology and green chemistry: green nanomedicine. Int J Nanomed. 2017;12:2957. doi: 10.2147/IJN.S127683. [PMC free article] [PubMed] [CrossRef] [Google Scholar]

[11]. Liu Z, Tabakman S, Welsher K, Dai H. Carbon nanotubes in biology and medicine: in vitro and in vivo detection, imaging and drug delivery. Nano Res. 2009;2:85-120. doi: 10.1007/s12274-0099009-8. [PMC free article] [PubMed] [CrossRef] [Google Scholar]

[12]. Orive G, Gascon AR, Hernández RM, DomínguezGil A, Pedraz JL. Techniques: new approaches to the delivery of biopharmaceuticals. Trends Pharmacol Sci. 2004;25:382-387. doi: 10.1016/j.tips.2004.05.006. [PubMed] [CrossRef] [Google Scholar]

[13]. Razzacki SZ, Thwar PK, Yang M, Ugaz VM, Burns MA. Integrated microsystems for controlled drug delivery. Adv Drug Deliv Rev. 2004;56:185-198. doi: 10.1016/j.addr.2003.08.012. [PubMed] [CrossRef] [Google Scholar]

[14]. Arayne MS, Sultana N, Qureshi F. nanoparticles in delivery of cardiovascular drugs. Pak J Pharm Sci. 2007;20:340-348. [PubMed] [Google Scholar]

[15]. Patra JK, Baek K-H. Green nanobiotechnology: factors affecting synthesis and characterization techniques. J Nanomater. 2014;2014:219. doi: 10.1155/2014/417305. [CrossRef] [Google Scholar]

[16]. Joseph RR, Venkatraman SS. Drug delivery to the eye: what benefits do nanocarriers offer? Nanomedicine. 2017;12:683-702. doi: 10.2217/nnm-2016-0379. [PubMed] [CrossRef] [Google Scholar]

[17]. Mirza AZ, Siddiqui FA. Nanomedicine and drug delivery: a mini review. Int Nano Lett. 2014;4:94. doi: 10.1007/s40089-014-0094-7. [CrossRef] [Google Scholar]

[18]. Rudramurthy GR, Swamy MK, Sinniah UR, Ghasemzadeh A. Nanoparticles: alternatives against drug-resistant pathogenic microbes. Molecules. 2016;21:836. doi: 10.3390/molecules21070836. [PMC free article] [PubMed] [CrossRef] [Google Scholar]

[19]. Lam P-L, Wong W-Y, Bian Z, Chui C-H, Gambari $\mathrm{R}$. Recent advances in green nanoparticulate systems for drug delivery: efficient delivery and safety concern. Nanomedicine. 2017;12:357-385. doi: $\quad 10.2217 / \mathrm{nnm}-2016-0305 . \quad$ [PubMed] [CrossRef] [Google Scholar]

[20]. Haba Y, Kojima C, Harada A, Ura T, Horinaka H, Kono K. Preparation of poly (ethylene glycol)modified poly (amido amine) dendrimers encapsulating gold nanoparticles and their heatgenerating ability. Langmuir. 2007;23:5243-5246. doi: 10.1021/la0700826. [PubMed] [CrossRef] [Google Scholar]

[21]. Shi X, Sun K, Baker JR., Jr Spontaneous formation of functionalized dendrimer-stabilized gold 
nanoparticles. J Phys Chem C. 2008;112:82518258. doi: 10.1021/jp801293a. [PMC free article] [PubMed] [CrossRef] [Google Scholar]

[22]. Park S-H, Oh S-G, Mun J-Y, Han S-S. Loading of gold nanoparticles inside the DPPC bilayers of liposome and their effects on membrane fluidities. Coll Surf B. 2006;48:112-118. doi: 10.1016/j.colsurfb.2006.01.006. [PubMed] [CrossRef] [Google Scholar]

[23]. de Villiers MM, Aramwit P, Kwon GS. Nanotechnology in drug delivery. New York: Springer; 2008. [Google Scholar]

[24]. Kabanov AV, Lemieux P, Vinogradov S, Alakhov V. Pluronic ${ }^{\circledR}$ block copolymers: novel functional molecules for gene therapy. Adv Drug Deliv Rev. 2002;54:223-233. doi: 10.1016/S0169409X(02)00018-2. [PubMed] [CrossRef] [Google Scholar]

[25]. Wang N, Feng Y. Elaborating the role of natural products-induced autophagy in cancer treatment: achievements and artifacts in the state of the art. BioMed Res Int. 2015;2015:934207. [PMC free article] [PubMed] [Google Scholar]

[26]. Ouattara B, Simard RE, Holley RA. Piette GJ-P, Bégin A: Antibacterial activity of selected fatty acids and essential oils against six meat spoilage organisms. Int J Food Microbiol. 1997;37:155-162. doi: 10.1016/S0168-1605(97)00070-6. [PubMed] [CrossRef] [Google Scholar]

[27]. Sharma G, Raturi K, Dang S, Gupta S, Gabrani R. Combinatorial antimicrobial effect of curcumin with selected phytochemicals on Staphylococcus epidermidis. J Asian Nat Prod Res. 2014;16:535541. doi: 10.1080/10286020.2014.911289. [PubMed] [CrossRef] [Google Scholar]

[28]. Abdelwahab SI, Sheikh BY, Taha MME, How CW, Abdullah R, Yagoub U, El-Sunousi R, Eid EE. Thymoquinone-loaded nanostructured lipid carriers: preparation, gastroprotection, in vitro toxicity, and pharmacokinetic properties after extravascular administration. Int J Nanomed. 2013;8:2163. doi: 10.2147/IJN.S44108. [PMC free article] [PubMed] [CrossRef] [Google Scholar]
[29]. Krauel K, Pitaksuteepong T, Davies NM, Rades T. Entrapment of bioactive molecules in poly (alkylcyanoacrylate) nanoparticles. Am J Drug Deliv. 2004;2:251-259. doi: 10.2165/00137696200402040-00005. [CrossRef] [Google Scholar]

[30]. Tan Q Liu W, Guo C, Zhai G. Preparation and evaluation of quercetin-loaded lecithin-chitosan nanoparticles for topical delivery. Int J Nanomed. 2011;6:1621. doi: 10.2217/nnm.11.142. [PMC free article] [PubMed] [CrossRef] [Google Scholar]

[31]. Sanna V, Roggio AM, Siliani S, Piccinini M, Marceddu S, Mariani A, Sechi M. Development of novel cationic chitosan-and anionic alginatecoated poly (D, L-lactide-co-glycolide) nanoparticles for controlled release and light protection of resveratrol. Int $\mathrm{J}$ Nanomed. 2012;7:5501. [PMC free article] [PubMed] [Google Scholar]

[32]. Casettari L, Illum L. Chitosan in nasal delivery systems for therapeutic drugs. J Control Release. 2014;190:189-200.

doi: 10.1016/j.jconrel.2014.05.003.

[PubMed] [CrossRef] [Google Scholar]

[33]. Obeid MA, Al Qaraghuli MM, Alsaadi M, Alzahrani AR, Niwasabutra K, Ferro VA. Delivering natural products and biotherapeutics to improve drug efficacy. Ther Deliv. 2017;8:947956. doi: 10.4155/tde-2017-0060. [PubMed] [CrossRef] [Google Scholar]

[34]. Miele E, Spinelli GP, Miele E, Di Fabrizio E, Ferretti E, Tomao S, Gulino A. Nanoparticle-based delivery of small interfering RNA: challenges for cancer therapy. Int J Nanomed. 2012;7:3637. [PMC free article] [PubMed] [Google Scholar]

[35]. McNamara K, Tofail SA. Nanosystems: the use of nanoalloys, metallic, bimetallic, and magnetic nanoparticles in biomedical applications. Phys Chem Chem Phys. 2015;17:27981-27995. doi: 10.1039/C5CP00831J. [PubMed] [CrossRef] [Google Scholar]

[36]. Saadeh Y, Vyas D. Nanorobotic applications in medicine: current proposals and designs. Am J Robot Surg. 2014;1:4-11. doi: 
10.1166/ajrs.2014.1010. [PMC free article] [PubMed] [CrossRef] [Google Scholar]

[37]. Oliveira ON, Jr, Iost RM, Siqueira JR, Jr, Crespilho FN, Caseli L. Nanomaterials for diagnosis: challenges and applications in smart devices based on molecular recognition. ACS Appl Mater Interfaces. 2014;6:14745-14766. doi: 10.1021/am5015056. [PubMed] [CrossRef] [Google Scholar]

[38]. De Jong WH, Borm PJ. Drug delivery and nanoparticles: applications and hazards. Int J Nanomed. 2008;3:133. doi: 10.2147/IJN.S596. [PMC free article] [PubMed] [CrossRef] [Google Scholar]

[39]. Holzinger M, Le Goff A, Cosnier S. Nanomaterials for biosensing applications: a review. Front Chem. 2014;2:63. doi: 10.3389/fchem.2014.00063. [PMC free article] [PubMed] [CrossRef] [Google Scholar]

[40]. Golovin YI, Gribanovsky SL, Golovin DY, Klyachko NL, Majouga AG, Master AM, Sokolsky M, Kabanov AV. Towards nanomedicines of the future: remote magneto-mechanical actuation of nanomedicines by alternating magnetic fields. J Control Release. 2015;219:43-60. doi: 10.1016/j.jconrel.2015.09.038. [PMC free article] [PubMed] [CrossRef] [Google Scholar]

[41]. Lu H, Wang J, Wang T, Zhong J, Bao Y, Hao H. Recent progress on nanostructures for drug delivery applications. J Nanomater. 2016;2016:20. [Google Scholar]

[42]. Blanco E, Shen H, Ferrari M. Principles of nanoparticle design for overcoming biological barriers to drug delivery. Nat Biotechnol. 2015;33:941. doi: 10.1038/nbt.3330. [PMC free article] [PubMed] [CrossRef] [Google Scholar]

[43]. Kumari A, Kumar V, Yadav S. Nanotechnology: a tool to enhance therapeutic values of natural plant products. Trends Med Res. 2012;7:34-42. doi: 10.3923/tmr.2012.34.42. [CrossRef] [Google Scholar]

[44]. Chen F, Ehlerding EB, Cai W. Theranostic nanoparticles. J Nucl Med. 2014;55:1919-1922. doi: 10.2967/jnumed.114.146019. [PMC free article] [PubMed] [CrossRef] [Google Scholar]
[45]. Swierczewska M, Han H, Kim K, Park J, Lee S. Polysaccharide-based nanoparticles for theranostic nanomedicine. Adv Drug Deliv Rev. 2016;99:70-84. doi: 10.1016/j.addr.2015.11.015. [PMC free article] [PubMed] [CrossRef] [Google Scholar]

[46]. Chen K, Chen X. Design and development of molecular imaging probes. Curr Top Med Chem. 2010;10:1227-1236.

doi: 10.2174/156802610791384225. [PMC free article] [PubMed] [CrossRef] [Google Scholar]

[47]. Yhee JY, Son S, Kim SH, Park K, Choi K, Kwon IC. Self-assembled glycol chitosan nanoparticles for disease-specific theranostics. J Control Release. 2014;193:202-213.

doi:

10.1016/j.jconrel.2014.05.009.

[PubMed]

[CrossRef] [Google Scholar]

[48]. Lee C-M, Jang D, Kim J, Cheong S-J, Kim E-M, Jeong M-H, Kim S-H, Kim DW, Lim ST, Sohn M$\mathrm{H}$, et al. Oleyl-Chitosan nanoparticles based on a dual probe for Optical/MR imaging in vivo. Bioconjug Chem. 2011;22:186-192. doi: 10.1021/bc100241a. [PubMed] [CrossRef] [Google Scholar]

[49]. Yang S-J, Lin F-H, Tsai H-M, Lin C-F, Chin H-C, Wong J-M, Shieh M-J. Alginate-folic acidmodified chitosan nanoparticles for photodynamic detection of intestinal neoplasms. Biomaterials. 2011;32:2174-2182.

doi:

10.1016/j.biomaterials.2010.11.039. [PubMed] [CrossRef] [Google Scholar]

[50]. Ryu JH, Na JH, Ko HK, You DG, Park S, Jun E, Yeom HJ, Seo DH, Park JH, Jeong SY. Noninvasive optical imaging of cathepsin $\mathrm{B}$ with activatable fluorogenic nanoprobes in various metastatic models. Biomaterials. 2014;35:23022311. doi: 10.1016/j.biomaterials.2013.11.080. [PubMed] [CrossRef] [Google Scholar]

[51]. Lapčík L, Lapcik L, De Smedt S, Demeester J, Chabrecek P. Hyaluronan: preparation, structure, properties, and applications. Chem Rev. 1998;98:2663-2684. doi: 10.1021/cr941199z. [PubMed] [CrossRef] [Google Scholar] 
[52]. Kim H, Kim Y, Kim I-H, Kim K, Choi Y. ROSresponsive activatable photosensitizing agent for imaging and photodynamic therapy of activated macrophages. Theranostics. 2014;4:1. doi: 10.7150/thno.7101. [PMC free article] [PubMed] [CrossRef] [Google Scholar]

[53]. Choi KY, Chung H, Min KH, Yoon HY, Kim K, Park JH, Kwon IC, Jeong SY. Self-assembled hyaluronic acid nanoparticles for active tumor targeting. Biomaterials. 2010;31:106-114. doi: 10.1016/j.biomaterials.2009.09.030. [PubMed] [CrossRef] [Google Scholar]

[54]. Kamat M, El-Boubbou K, Zhu DC, Lansdell T, Lu X, Li W, Huang X. Hyaluronic acid immobilized magnetic nanoparticles for active targeting and imaging of macrophages. Bioconjug Chem. 2010;21:2128-2135. doi: 10.1021/bc100354m. [PubMed] [CrossRef] [Google Scholar]

[55]. Arpicco S, Lerda C, Dalla Pozza E, Costanzo C, Tsapis N, Stella B, Donadelli M, Dando I, Fattal E, Cattel L. Hyaluronic acid-coated liposomes for active targeting of gemcitabine. Eur J Pharm Biopharm. 2013;85:373-380. doi: 10.1016/j.ejpb.2013.06.003. [PubMed] [CrossRef] [Google Scholar]

[56]. Wang G, Gao S, Tian R, Miller-Kleinhenz J, Qin Z, Liu T, Li L, Zhang F, Ma Q, Zhu L. Theranostic hyaluronic acid-iron micellar nanoparticles for magnetic-field-enhanced in vivo cancer chemotherapy. ChemMedChem. 2018;13:78-86. doi: 10.1002/cmdc.201700515. [PubMed] [CrossRef] [Google Scholar]

[57]. Choi KY, Jeon EJ, Yoon HY, Lee BS, Na JH, Min KH, Kim SY, Myung S-J, Lee S, Chen X. Theranostic nanoparticles based on PEGylated hyaluronic acid for the diagnosis, therapy and monitoring of colon cancer. Biomaterials. 2012;33:6186-6193.

doi: 10.1016/j.biomaterials.2012.05.029. [PMC free article] [PubMed] [CrossRef] [Google Scholar]

[58]. Gombotz WR, Wee S. Protein release from alginate matrices. Adv Drug Deliv Rev. 1998;31:267-285. doi: 10.1016/S0169-
409X(97)00124-5. [PubMed] [CrossRef] [Google Scholar]

[59]. Lee KY, Mooney DJ. Alginate: properties and biomedical applications. Prog Polym Sci. 2012;37:106-126. doi: 10.1016/j.progpolymsci.2011.06.003. [PMC free article] [PubMed] [CrossRef] [Google Scholar]

[60]. Baghbani F, Moztarzadeh F, Mohandesi JA, Yazdian F, Mokhtari-Dizaji M. Novel alginatestabilized doxorubicin-loaded nanodroplets for ultrasounic theranosis of breast cancer. Int J Biol Macromol. 2016;93:512-519. doi: 10.1016/j.ijbiomac.2016.09.008. [PubMed] [CrossRef] [Google Scholar]

[61]. Podgórna K, Szczepanowicz K, Piotrowski M, Gajdošová $\mathrm{M}$, Štěpánek $F$, Warszyński $P$. Gadolinium alginate nanogels for theranostic applications. Coll Surf B. 2017;153:183-189. doi: 10.1016/j.colsurfb.2017.02.026.

[PubMed] [CrossRef] [Google Scholar]

[62]. Moscovici M. Present and future medical applications of microbial exopolysaccharides. Front Microbiol. 1012;2015:6. [PMC free article] [PubMed] [Google Scholar]

[63]. Ding Z, Liu P, Hu D, Sheng Z, Yi H, Gao G, Wu Y, Zhang P, Ling S, Cai L. Redox-responsive dextran based theranostic nanoparticles for nearinfrared/magnetic resonance imaging and magnetically targeted photodynamic therapy. Biomater Sci. 2017;5:762-771. doi: 10.1039/C6BM00846A. [PubMed] [CrossRef] [Google Scholar]

[64]. Hong S-P, Kang SH, Kim DK, Kang BS. Paramagnetic nanoparticle-based targeting theranostic agent for c6 rat glioma cell. J Nanomater. 2016;2016:7617894. doi: 10.1155/2016/7617894. [CrossRef] [Google Scholar]

[65]. Mignani S, El Kazzouli S, Bousmina M, Majoral JP. Expand classical drug administration ways by emerging routes using dendrimer drug delivery systems: a concise overview. Adv Drug Deliv Rev. 2013;65:1316-1330.

doi: 
10.1016/j.addr.2013.01.001. [PubMed] [CrossRef] [Google Scholar]

[66]. Lounnas V, Ritschel T, Kelder J, McGuire R, Bywater RP, Foloppe N. Current progress in structure-based rational drug design marks a new mindset in drug discovery. Comput Struc Biotechnol J. 2013;5:e201302011. doi: 10.5936/csbj.201302011. [PMC free article] [PubMed] [CrossRef] [Google Scholar]

[67]. Mavromoustakos T, Durdagi S, Koukoulitsa C, Simcic M, Papadopoulos M, Hodoscek M, Golic Grdadolnik S. Strategies in the rational drug design. Curr Med Chem. 2011;18:2517-2530. doi: $10.2174 / 092986711795933731$.

[PubMed] [CrossRef] [Google Scholar]

[68]. Wong PT, Choi SK. Mechanisms of drug release in nanotherapeutic delivery systems. Chem Rev. 2015;115:3388-3432. doi: 10.1021/cr5004634. [PubMed] [CrossRef] [Google Scholar]

[69]. Prachayasittikul V, Worachartcheewan A, Shoombuatong W, Songtawee N, Simeon S, Prachayasittikul V, Nantasenamat C. Computeraided drug design of bioactive natural products. Curr Top Med Chem. 2015;15:1780-1800. doi: 10.2174/1568026615666150506151101. [PubMed] [CrossRef] [Google Scholar]

[70]. Chen G, Roy I, Yang C, Prasad PN. Nanochemistry and nanomedicine for nanoparticle-based diagnostics and therapy. Chem Rev. 2016;116:2826-2885. doi: 10.1021/acs.chemrev.5b00148. [PubMed] [CrossRef] [Google Scholar]

[71]. Pelaz B, Alexiou C, Alvarez-Puebla RA, Alves F, Andrews AM, Ashraf S, Balogh LP, Ballerini L, Bestetti A, Brendel C, Bosi S. Diverse applications of nanomedicine. Acs Nano. 2017;11:2313-2381. doi: 10.1021/acsnano.6b06040. [PMC free article] [PubMed] [CrossRef] [Google Scholar]

[72]. Mattos BD, Rojas OJ, Magalhaes WLE. Biogenic silica nanoparticles loaded with neem bark extract as green, slow-release biocide. J Clean Prod. 2017;142:4206-4213. doi: 10.1016/j.jclepro.2016.11.183. [CrossRef] [Google Scholar]
[73]. Kinnear C, Moore TL, Rodriguez-Lorenzo L, Rothen-Rutishauser B, Petri-Fink A. Form follows function: nanoparticle shape and its implications for nanomedicine. Chem Rev. 2017;117:1147611521. doi: 10.1021/acs.chemrev.7b00194. [PubMed] [CrossRef] [Google Scholar]

\section{Cite this article as :}

Ranajit Nath, Ratna Roy, Gourav Barai, Shishir Bairagi, Supratip Manna, Rajarshi Chakraborty, "Modern Developments of Nano Based Drug Delivery System by Combined with PhytochemicalsPresenting New Aspects", International Journal of Scientific Research in Science and Technology (IJSRST), Online ISSN : 2395-602X, Print ISSN : 23956011, Volume 8 Issue 4, pp. 107-129, July-August 2021. Available at

doi : https://doi.org/10.32628/IJSRST218422

Journal URL : https://ijsrst.com/IJSRST218422 